\title{
Recurrent Blood Pressure Rise after Treatment with Anti-vascular Endothelial Growth Factor Agents Wiederholter Blutdruckanstieg nach Injektionen mit Anti-vascular endothelial Growth Factor
}

Authors

Iris Wyssmüller, Karen Schaal, Sebastian Wolf, Martin Zinkernagel

Affiliation

Department of Ophthalmology, Inselspital Universitätsspital Bern, Bern, Switzerland

Key words

intravitreal injection, blood pressure rise, aflibercept

Schlüsselwörter

intravitreale Injektion, Blutdruckanstieg, Aflibercept

$\begin{array}{ll}\text { received } & 24.6 .2019 \\ \text { accepted } & 7.12 .2019\end{array}$

Bibliography

DOI https://doi.org/10.1055/a-1081-1635

Published online 24.2.2020 | Klin Monatsbl Augenheilkd 2020; 237: 454-457 @ Georg Thieme Verlag KG Stuttgart . New York | ISSN 0023-2165

Correspondence

Iris Wyssmüller

Inselspital Universitätsspital Bern, Department of

Ophthalmology

Freiburgstrasse 1, 3010 Bern, Switzerland

Phone: + 41794784199 , Fax: + 41316644779

iris.wyssmueller@gmail.com

\section{ABSTRACT}

Background It has previously been shown that the process of anti-vascular endothelial growth factor (VEGF) injections can lead to a significant increase of blood pressure. The aim of this study was to investigate whether this blood pressure increase was reproducible with repeated anti-VEGF injections.

Patients and Methods Patients with a systolic blood pressure of $\geq 180 \mathrm{mmHg}$ during previous injections who were scheduled for further injections were asked to participate in this study. Systolic as well as diastolic blood pressure was measured before, during, and after the intravitreal injection process.

Results Thirty-nine patients ( 21 females, 18 males) with a mean age of 75 years (range 34-94 years) were included in this extension of the FEAR study. At first, clinical systolic blood pressure rose from an average of $157.3 \pm 5.9 \mathrm{mmHg}$ to $175 \pm$ $6.7 \mathrm{mmHg}$ at the time of the injection process $(p<0.01)$. Diastolic blood pressure rose from an average of $75.72 \pm$ $4.2 \mathrm{mmHg}$ to $84.44 \pm 7.3 \mathrm{mmHg}(p<0.13)$ at the time of the injection process. Overall, the majority of the participants ( $56 \%, \mathrm{~N}=22$ ) had a systolic blood pressure of $\geq 180 \mathrm{mmHg}$.

Conclusions Our results show that the blood pressure increase occurs persistently during the injection process in some patients. Repeated episodes of severe hypertension may predispose patients to cardiovascular events, especially those with concomitant cardiovascular risk factors.

\section{ZUSAMMENFASSUNG}

Hintergrund Bereits vorgängig wurde gezeigt, dass der Verabreichungsprozess von Injektionen mit Anti-vascular endothelial Growth Factor (Anti-VEGF) zu einem signifikanten Blutdruckanstieg führen kann. Das Ziel dieser Studie war die Untersuchung der Reproduzierbarkeit dieses Blutdruckanstiegs mit wiederholten Anti-VEGF-Injektionen.

Patienten und Methoden Patienten mit einem systolischen Blutdruckwert $\geq 180 \mathrm{mmHg}$ während vorhergehender Injektionen in der FEAR-Studie, für welche weitere Injektionen geplant waren, wurden gefragt, ob sie an der Studie teilnehmen wollen. Der systolische wie auch der diastolische Blutdruck wurden vor, während und nach dem intravitrealen Injektionsprozess gemessen.

Ergebnisse 39 Patienten (21 Frauen, 18 Männer) mit einem Durchschnittsalter von 75 Jahren (im Alter von 34 bis 94 Jahren) wurden in dieser Erweiterung der FEAR-Studie eingeschlossen. Der systolische Blutdruck stieg ausgehend von einem Mittelwert von $157 \pm 5,9 \mathrm{mmHg}$ bei Ankunft der Patienten auf $175 \pm 6,7 \mathrm{mmHg}$ zum Zeitpunkt des Injektionsprozesses an $(p>0,01)$. Der diastolische Blutdruck stieg ausgehend von einem Mittelwert von 75,72 $\pm 4,2 \mathrm{mmHg}$ bei Ankunft der Patienten auf $84,44 \pm 7,3 \mathrm{mmHg}$ zum Zeitpunkt des Injektionsprozesses an $(p<0,13)$. Insgesamt zeigte die Mehrheit der Teilnehmer $(56 \%, n=22)$ einen systolischen Blutdruck von $\geq 180 \mathrm{mmHg}$. 
Schlussfolgerungen Unsere Resultate zeigen, dass der Blutdruckanstieg während des Injektionsprozesses bei einigen Patienten konstant auftritt. Wiederholte Episoden von schwerer
Hypertonie können zu kardiovaskulären Ereignissen prädisponieren, besonders bei Patienten mit zusätzlich begleitenden kardiovaskulären Risikofaktoren.

\section{Background}

Age-related macular degeneration (AMD), diabetic macular edema (DME) as well as macular edema due to retinal vein occlusions (RVO) [1,2] are three of the most common macular diseases in the Western world. All, if left untreated, may lead to severe vision loss. With the introduction of anti-vascular endothelial growth factor (Anti-VEGF) agents about two decades ago, a highly effective drug for the treatment of neovascular AMD as well as macular edema secondary to diabetes and vein occlusion has become available. Since then, many trials have shown that injections with Anti-VEGF agents may prevent further loss of visual acuity (VA) or may even lead to an increase of VA [3-6]. Anti-VEGF treatment has emerged as one of the most favorable therapies for macular diseases and many people today receive intravitreal injections with Anti-VEGF agents.

Due to this success, the number of injections has increased considerably. There has been an increasing debate about potential systemic side effects, such as an increased risk of systemic vascular events [7]. In addition to systemic exposure to anti-VEGF [8], other factors such as cardiovascular risk factors or, possibly, repeated blood pressure decompensation may be responsible for the observed increase in cardiovascular events in patients receiving anti-VEGF injections [9].

In a previous study, we were able to show an association of intravitreal injections with a transient, significant increase in blood pressure. In this recent study, $11 \%$ of the participants had a systolic blood pressure of $\geq 200 \mathrm{mmHg}$ during the injection process [10].

The aim of the present study was to investigate whether patients experience a repeated blood pressure rise with repeated intravitreal injections.

\section{Participants and Methods}

The study was performed according to the International Ethical Guidelines for Biomedical Research Involving Human Subjects and approved by the ethics review board of Bern, Switzerland.

The study was designed as a prospective, descriptive observational study in a tertiary referral center. All patients were previously informed about the procedures and goals of the study. Informed consent for blood pressure measurements during injections was obtained for all participants before entering the study.

Participants previously included in the "Following Excitement and Anxiety Response under intravitreal Injection - the FEAR study" who had a blood pressure of $\geq 180 \mathrm{mmHg}$ during the first set of measurements were scheduled for further injections and included into the study. This cohort of FEAR study patients was advised to have their blood pressure checked at their general practitioner. Each participant was evaluated routinely for visual acuity and received biomicroscopic fundus examination before injection.
The protocol for blood pressure measurement was as follows: The first blood pressure measurement was taken on the right arm 30 min before injection in the waiting area (SYS \& DIA 1), the second measurement 5 min before injection in the preparing room (SYS \& DIA 2), the third measurement during the injection (SYS \& DIA 3), and the last measurement 15 min after the injection (SYS \& DIA 4). Systolic as well as diastolic blood pressure was measured with a portable noninvasive recording device.

Data analysis was performed using GraphPad Prism version 5.02 for Windows (GraphPad Software, La Jolla, CA, USA, www. graphpad.com and SigmaPlot version 11.0). Repeated measures ANOVA was used to compare data at different time points. A $p$ value of $\leq 0.05$ was considered to be statistically significant.

\section{Results}

Thirty-nine patients, of which $54 \%(\mathrm{~N}=21)$ were women and $46 \%$ $(\mathrm{N}=18)$ were men, were included in this study. The average age was 75 years (median $=78$ years, $\min =34$ years, $\max =94$ years). About one-third of these patients had neovascular age-related macular degeneration ( $\mathrm{nAMD})(36 \%, \mathrm{~N}=14)$. Another third had macular edema due to retinal vein occlusions (RVO) (31\%, $N=12)$, and $23 \%(n=9)$ had diabetic macular edema. The majority of these patients were already familiar with the injection procedure, with an average number of 30 injections (median = 23 Injections, $\min =4$, $\max =95$ ). The mean increase of systolic blood pressure from the first measurement to the measurement at the time of injection was significant ( $\bullet$ Table $\mathbf{1}$ and $\mathbf{2}$ ).

Overall, the majority of all the participants $(56 \%, N=22)$ had a systolic blood pressure of $\geq 180 \mathrm{mmHg}$ in one of the four measurements. However, there was no significant change in diastolic blood pressure at the four predefined time points in the study protocol ( $\vee$ Table 3 and 4 ).

\section{Conclusions}

The results show that there is a significant rise in blood pressure during the intravitreal injection process. These results support the findings of the study of Berger et al. [10] and show that the blood pressure increase is reproducible and fairly consistent during the intravitreal injection process.

The question arises, whether a repeated blood pressure rise may be responsible for the higher incidence of cardiovascular incidents in a subpopulation of patients receiving anti-VEGF injections. According to the European Society of Cardiology and the European Society of Hypertension, a systolic blood pressure of $\geq 180 \mathrm{mmHg}$ and/or diastolic blood pressure of $\geq 110 \mathrm{mmHg}$ is called severe hypertension (Grade 3). If the increase in blood pressure is related with organ damage, the term hypertensive emergency is used [11]. 
- Table 1 Systolic blood pressure values at four different time points (SYS1 - SYS4).

\begin{tabular}{|l|l|l|l|l|}
\hline & $\begin{array}{l}\text { SYS1 (30 } \mathbf{~ m i n} \text { prior } \\
\text { to injection) }\end{array}$ & $\begin{array}{l}\text { SYS2 (5 min prior } \\
\text { to injection) }\end{array}$ & $\begin{array}{l}\text { SYS3 (during the } \\
\text { injection) }\end{array}$ & $\begin{array}{l}\text { SYS4 (15 min after } \\
\text { injection) }\end{array}$ \\
\hline Minimum & 123 & 110 & 116 & 114 \\
\hline Median & 161 & 166 & 180 & 165 \\
\hline Maximum & 202 & 216 & 221 & 208 \\
\hline Mean $(95 \% \mathrm{Cl})$ & $157.3(151.5-163.2)$ & $167(160-173.9)$ & $175(168.4-181.7)$ & $161.4(154.6-168.3)$ \\
\hline Std. deviation & 18.1 & 21.45 & 20.59 & 21.11 \\
\hline Std. error of mean & 2.899 & 3.434 & 3.297 & 3.38 \\
\hline
\end{tabular}

- Table 2 Mean differences and p values of the systolic blood pressure values at four different time points (SYS1 - SYS4).

\begin{tabular}{|l|l|l|l|l|}
\hline Tukey's multiple comparisons test & Mean difference & $\mathbf{9 5 \%} \mathbf{C l}$ of mean difference & Adjusted p value & Significant \\
\hline SYS1 vs. SYS2 & -9.641 & $-21.61-2.332$ & 0.1605 & No \\
\hline SYS1 vs. SYS3 & -17.69 & $-29.67-5.719$ & 0.001 & Yes \\
\hline SYS1 vs. SYS4 & -4.077 & $-16.05-7.896$ & 0.8129 & No \\
\hline SYS2 vs. SYS3 & -8.051 & $-20.02-3.922$ & 0.3033 & No \\
\hline SYS2 vs. SYS4 & 5.564 & $-6.409-17.54$ & 0.6233 & No \\
\hline SYS3 vs. SYS4 & 13.62 & $1.642-25.59$ & 0.0189 & Yes \\
\hline
\end{tabular}

- Table 3 Diastolic blood pressure values at four different time points (DIA 1 - DIA 4).

\begin{tabular}{|l|c|c|c|c|}
\hline & $\begin{array}{l}\text { DIA 1 (30 } \mathbf{~ m i n ~ p r i o r ~} \\
\text { to injection) }\end{array}$ & $\begin{array}{l}\text { DIA 2 (5 min prior } \\
\text { to injection) }\end{array}$ & $\begin{array}{l}\text { DIA 3 (during the } \\
\text { injection) }\end{array}$ & $\begin{array}{l}\text { DIA 4 (15 min after } \\
\text { injection) }\end{array}$ \\
\hline Minimum & 52 & 51 & 51 & 56 \\
\hline Median & 73 & 73 & 153 & 76 \\
\hline Maximum & 107 & $79.08(73.36-84.79)$ & $84.44(77.1-91.77)$ & $77.54(72.63-82.45)$ \\
\hline Mean (95\% Cl) & $75.72(71.52-79.91)$ & 17.65 & 22.63 & 15.14 \\
\hline Std. Deviation & 12.95 & 2.822 & 3.624 & 2.425 \\
\hline Std. Error of Mean & 2.073 & & & \\
\hline
\end{tabular}

- Table 4 Mean differences and p values of the systolic blood pressure values at four different time points (DIA 1 - DIA 4).

\begin{tabular}{|l|l|l|l|l|}
\hline Tukey's multiple comparisons test & Mean difference & $\mathbf{9 5 \%} \mathrm{Cl}$ of mean difference & Adjusted p value & Significant \\
\hline DIA 1 vs. DIA 2 & -3.359 & $-13.63-6.913$ & 0.8306 & No \\
\hline DIA 1 vs. DIA 3 & -8.718 & $-18.99-1.554$ & 0.1266 & No \\
\hline DIA 1 vs. DIA 4 & -1.821 & $-12.09-8.452$ & 0.9675 & No \\
\hline DIA 2 vs. DIA 3 & -5.359 & $-15.63-4.913$ & 0.5294 & No \\
\hline DIA 2 vs. DIA 4 & 1.538 & $-8.734-11.81$ & 0.9799 & No \\
\hline DIA 3 vs. DIA 4 & 6.897 & $-3.375-17.17$ & 0.3046 & No \\
\hline
\end{tabular}

It is known that repetitive hypertensive urgencies are associated with an increased risk for subsequent cardiovascular events [12]. This may be especially important for patients having repeated episodes of severe hypertension (hypertensive urgencies) and a concomitant microangiopathy, which is known to be associated with small artery fibrinoid necrosis in the kidney, retina, and brain [11].
In our study, $59 \%$ of the participants $(\mathrm{N}=23)$ had an overall increase of systolic blood pressure $\geq 20 \mathrm{mmHg}$ during the injection process. According to the ESC/ESH Guidelines, such fluctuations constitute an additional risk factor for organ dysfunction [13].

Limitations of the study are the lack of long-time monitoring, a lack of continuous blood pressure measurement $24 \mathrm{~h}$ before and 
$24 \mathrm{~h}$ after the injection process, and the relatively small study population as well as the absence of a sham group.

In conclusion, we were able to demonstrate that the intravitreal injection process can lead to a consistent and repeated blood pressure rise. In patients experiencing severe hypertension during the injection process and who receive anti-VEGF treatment on a regular basis, this may occur on a monthly basis. Furthermore, patients with a recent history of cardiovascular events or other concomitant risk factors, such as diabetes, may be especially at risk for developing new cardiovascular events due to a severe blood pressure rise occurring during the intravitreal injection process.

\section{Conflict of Interest}

The authors declare that they have no conflict of interest.

\section{References}

[1] Reitmeir P, Linkohr B, Heier M et al. Common eye diseases in older adults of southern Germany: results from the KORA-Age study. Age Ageing 2017; 46: 481-486

[2] Klein R, Klein BE. The prevalence of age-related eye diseases and visual impairment in aging: current estimates. Invest Ophthalmol Vis Sci 2013; 54: ORSF5-ORSF13

[3] Brown DM, Nguyen QD, Marcus DM et al. Long-term outcomes of ranibizumab therapy for diabetic macular edema: the 36-month results from two phase III trials: RISE and RIDE. Ophthalmology 2013; 120: 2013-2022

[4] Heier JS, Korobelnik JF, Brown DM et al. Intravitreal Aflibercept for Diabetic Macular Edema: 148-Week Results from the VISTA and VIVID Studies. Ophthalmology 2016; 123: 2376-2385
[5] Sarwar S, Clearfield E, Soliman MK et al. Aflibercept for neovascular agerelated macular degeneration. Cochrane Database Syst Rev 2016; 2: CD011346

[6] Clark WL, Boyer DS, Heier JS et al. Intravitreal Aflibercept for Macular Edema Following Branch Retinal Vein Occlusion: 52-Week Results of the VIBRANT Study. Ophthalmology 2016; 123: 330-336

[7] Ueta T, Noda Y, Toyama T et al. Systemic vascular safety of ranibizumab for age-related macular degeneration: systematic review and meta-analysis of randomized trials. Ophthalmology 2014; 121: 2193-2203.e1-7

[8] Avery RL, Castellarin AA, Steinle NC et al. Systemic Pharmacokinetics and Pharmacodynamics of Intravitreal Aflibercept, Bevacizumab, and Ranibizumab. Retina 2017; 37: 1847-1858

[9] Wells JA, Glassman AR, Ayala AR et al. Aflibercept, Bevacizumab, or Ranibizumab for Diabetic Macular Edema: Two-Year Results from a Comparative Effectiveness Randomized Clinical Trial. Ophthalmology 2016; 123 : 1351-1359

[10] Berger V, Munk MR, Lersch F et al. Association of Intravitreal Injections with Blood Pressure Increase: The Following Excitement and Anxiety Response Under Intravitreal Injection Study. JAMA Ophthalmol 2019; 137: 87-90. doi:10.1001/jamaophthalmol.2018.4892

[11] Williams B, Mancia G, Spiering W et al. 2018 ESC/ESH Guidelines for the management of arterial hypertension: The Task Force for the management of arterial hypertension of the European Society of Cardiology and the European Society of Hypertension: The Task Force for the management of arterial hypertension of the European Society of Cardiology and the European Society of Hypertension. J Hypertens 2018; 36: 19532041

[12] Vlcek M, Bur A, Woisetschlager C et al. Association between hypertensive urgencies and subsequent cardiovascular events in patients with hypertension. J Hypertens 2008; 26: 657-662

[13] Goldman L, Caldera DL. Risks of general anesthesia and elective operation in the hypertensive patient. Anesthesiology 1979; 50: 285-292 